Abstracta Iranica

Revue bibliographique pour le domaine irano-aryen

Volume 34-35-36 | 2017

Comptes rendus des publications de 2011-2013

\title{
Radosław Tarasewicz. On the Hazannu in the Neo- Babylonian and Persian Periods
}

\section{Astrid Nunn}

\section{(2) OpenEdition}

1 Journals

\section{Édition électronique}

URL : http://journals.openedition.org/abstractairanica/41591

DOI : 10.4000/abstractairanica.41591

ISSN : 1961-960X

Éditeur :

CNRS (UMR 7528 Mondes iraniens et indiens), Éditions de l'IFRI

Référence électronique

Astrid Nunn, "Radosław Tarasewicz. On the Hazannu in the Neo-Babylonian and Persian Periods », Abstracta Iranica [En ligne], Volume 34-35-36 | 2017, document 44, mis en ligne le 15 juillet 2016, consulté le 05 octobre 2020. URL : http://journals.openedition.org/abstractairanica/41591 ; DOI : https://doi.org/10.4000/abstractairanica.41591

Ce document a été généré automatiquement le 5 octobre 2020.

Tous droits réservés 


\title{
Radosław Tarasewicz. On the Hazannu in the Neo-Babylonian and Persian Periods
}

\author{
Astrid Nunn
}

\section{RÉFÉRENCE}

Radosław Tarasewicz. « On the Hazannu in the Neo-Babylonian and Persian Periods ». Palamedes: A Journal of Ancient History, vol. 7, 2012, p. 25-42.

1 Nos connaissances sur l'organisation de la Babylonie du $\mathrm{I}^{\mathrm{er}}$ mill. comporte des lacunes. L'une d'entre elles concerne le personnage clef qu'était le Hazannu. Il apparaît à la période d'Ur III puis ne cesse d'exister jusqu'à l'époque achéménide. Toujours nommé par le roi, il le représente dans la province. Sa fonction est à la fois religieuse et séculaire. L'A. présente un inventaire provisoire de nos connaissances à l'aide des documents de Borsippa, Sippar et Uruk conservés au British Museum.

\section{AUTEURS}

\section{ASTRID NUNN}

Université de Munich 